\title{
SYSTEM ALLOWING ADHESION FORCE CHANGE OF ROAD VEHICLE
}

\author{
Petr Jilek, Ivo Sefcik, Jan Verner, Jan Berg \\ University of Pardubice, Czech Republic \\ petr.jilek@upce.cz,ivo.sefcik@upce.cz,jan.verner@upce.cz, jan.berg@upce.cz
}

\begin{abstract}
Bringing the car into a skid is realised by the adhesion force decrease. This can be reached either by a coefficient of adhesion decrease or decrease of a radial reaction on the vehicle's wheel. For the purpose to the vehicle's behaviour change according to stability we chose the way of radial reaction change. To decrease the adhesion force transferred by the vehicle's wheels, the required part of radial reaction of a particular vehicle's wheel was transferred to the road, out of the vehicle's wheels, using additional auxiliary wheels. The auxiliary wheel units are connected to suspension arms. The article contains individual currently used ways for the adhesion force change and the unique way in the form of the system SlideWheel designed by the authors. The system SlideWheel, which was designed by the authors of this article, consists of three circuits. The first circuit is the mechanical part of the wheel unit, the second one is designed in the form of a hydraulic system and the third circuit is an electrical system used to control the wheel unit's lift through the hydraulic system. The system was designed to be used for experimental measurement purposes in education in order to experimentally simulate oversteer or understeer of the vehicle. The real measured data from a particular drive test are stated and evaluated in the conclusion. The measurement is implemented on a special experimental vehicle equipped with the SlideWheel system. Based on the experimental measurements, we have come to the conclusion that using the SW system, it is possible to change the adhesion force of a road vehicle. The paper deals with a new system for radial reaction change of vehicle wheels. This system has minimal added weight to the vehicle. At the same time, none of the components exceeds the ground plan of the vehicle. With the newly created system, it is possible to reduce radial reactions on any car wheel. The measured results are consistent with the vehicle's ride on sliding surfaces.
\end{abstract}

Keywords: road vehicle, adhesion, tyres, SlideWheel.

\section{Introduction}

With regard to the advent of self-driving road vehicles, it is necessary to put great emphasis on the road safety. Safety is largely affected by the driver's skills, car design maturity [1], tyre quality [2] and, last but not least, the maintenance level and quality [3;4]. In any case, there are always the laws of physics that even state-of-the-art electronic systems are not able to get around [5]. The main cause of a traffic accident is skidding, which is affected by the car design, tyre conditions, driving style, as well as the car parameters [6;7]. From this perspective, cars are tested for stability, especially in the longitudinal direction, i.e., resistance to longitudinal shear. Verification of the car behaviour can be done in the form of test drives under real conditions [7;8]. These tests are mainly carried out on preseries cars. In the early development of a vehicle or its systems, it is necessary to carry out experimental measurements under model conditions at a lower speed from the point of view of the testing safety.

Driving a car at a skid level at 'safe' speed can be achieved in two basic ways. The first way is to reduce the adhesion coefficient between the tyre and the road. This can be done by using a sliding surface in the form of a slide film or slide paint [9]. To reduce the coefficient from the side of the car wheel, it is possible to achieve the Easy Drift Ring slide tyres. The second way to reduce adhesion is to reduce the radial reaction of the car wheels. This can be achieved by means of an additional frame with support wheels. They carry the required part of the radial reactions, the amount of which is needed to reduce the radial response of the car wheels. This system is commercially available under the name SkidCar. The disadvantage of the SkidCar system is that the frame exceeds the design of the car and there is also a significant increase in the car kerb weight. The results, collected during the experimental test, are presented and discussed.

\section{Materials and methods}

The workplace of the authors works with a system that, by turning the rear axle wheels, will delay the formation of the car skidding. The authors' workplace has only limited spaces where sliding surfaces cannot be used; therefore, we changed the adhesion coefficient by reducing the radial reactions on the car wheels. The alternative SkidCar exceeds the design of the vehicle with its 
dimensions, and is therefore inappropriate for the needs of testing the developed rear axle wheel steering system. We proceeded to develop our own system called SlideWheel (SW); see Fig. 1.

We had to find a way to skid a car at the so-called "safe" speed for the initial testing of the developed system. We used a speed at which collision does not have serious consequences and, at the same time, it is possible to objectively control the car to a limited extent based on the driver's experience as the safe speed; that is, $50 \mathrm{~km}^{-1}$.

The car side skid that occurs when the longitudinalforce is greater than the lateral links between the tyre and the road is selected as the limit state [10]. These contact links are affected by the maximum adhesion force vector. One of the primary options to reduce the risk of skidding in the vehicle's construction is to use simulation programs [11;12], followed by real test drives, where the mutual agreement of the results is verified. Relation (1), which describes the size of the lateral force which must be equal to the centrifugal force, applies for the movement of the vehicle at the skid level.

$$
F_{a d_{y}}=\left(G \cdot \cos \beta+F_{o} \cdot \sin \beta\right) \cdot \varphi,
$$

where $F_{a d y}-$ side force, N;

$F_{o}$ - centrifugal force, $\mathrm{N}$;

$G$ - gravity of the vehicle, N;

$\varphi$ - coefficient of adhesion;

$\beta$ - slant slope of the road, degrees.

The SW system requirements are to provide the necessary lightening of the car wheel with minimum lifting of the sprung masses. At the same time, the car's behaviour cannot be significantly affected. The SlideWheel system is an additional device to complement the chassis of the experimental car. It is an electro-hydraulic system that allows the car to achieve different adhesion conditions. The system consists of four wheel units, a hydraulic unit with a control circuit. It is possible to partially lighten the front axle, the rear axle or both axles at the same time or any wheel with an electronically controlled hydraulic circuit. This can be done in any range of radial reactions. The SlideWheel system is built directly for the experimental vehicle. The dominant element in relation to the flexibility of the SW system and the noise emitted during the drive are the support wheels, where the determination of their radial stiffness is detailed in [2] and the noise emitted in [13].

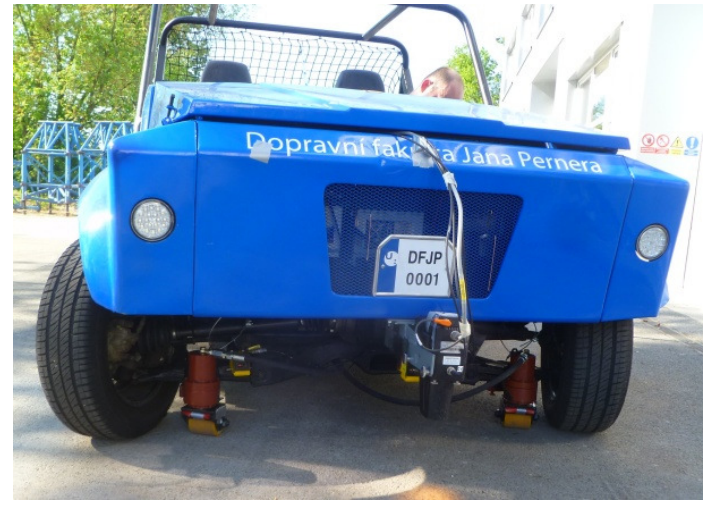

Fig. 1. Experimental vehicle with SlideWheel

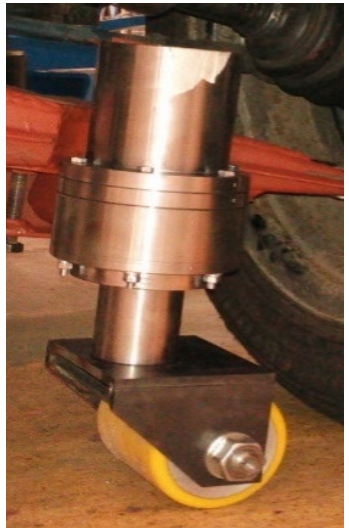

Fig. 2. Compact wheel unit

We used a slalom test drive to verify the behaviour of the vehicle with the SW system. At the same time, we compared the measured waveforms of the experimental vehicle with the SW system with the experimental vehicle drive on a sliding surface. The essence of the test is for the vehicle to pass through a defined corridor between the cones at a predetermined speed. This speed is a speed, at which it is possible to drive through the corridor on the sliding surface. The construction of the corridor is evident from Fig. 3. We conducted the test drive for $50 \%$ radial response on the car wheels.

We recorded the following quantities to monitor the vehicle behaviour during the test drive [10]. The speed $v$, slip angle $\varphi$ and the vehicle turning speed $\omega$ were measured using the Correvit. The 
steering wheel turning angle $\beta_{v}$ was measured by an analogue cable position sensor, which was wound on the steering column and further calculated according to relation (2). The longitudinal $a_{y}$ and longitudinal $a_{x}$ acceleration using the acceleration sensor and the body pitch angle $\beta_{i}$ were calculated from the signals of a pair of ultrasound distance sensors located at the place of the centre of gravity along the sides of the car.

$$
\beta_{v}=\frac{180 \cdot l_{l}}{\pi \cdot r_{v}}-\beta_{v o},
$$

where $\beta_{v}$-actual steering angle, degrees;

$\beta_{v o}$ - steering angle for compensatory measurements, degrees;

$l_{l}$ - ejecting the sensor rope, $\mathrm{m}$;

$r_{v}$ - radius of the steering shaft, $\mathrm{m}$.

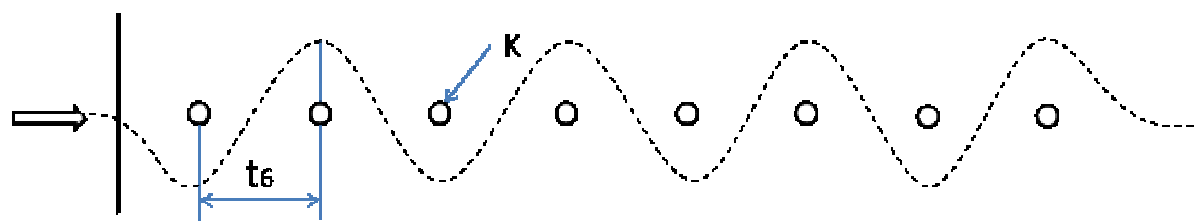

Fig. 3. Corridorwithtrajectoryof car forslalom test: $t_{6}$ - distance between cones, $K$-cone

Before we started a series of test drives, we had performed compensation measurements. Compensation measurements are used to verify the functionality of the measuring chain and as a data set for subsequent off-time correction. The correction is necessary in terms of removing mounting and technical derogations in the installation of the measuring instrument on the car and to eliminate the tilting of the car body when changing the radial reactions on the car wheels. The compensation measurements were performed in the form of seven repeated measurements at direct steady drive in both directions on a $30 \mathrm{~m}$ track. In this way, we obtained quasi-static waveforms of the measured quantities for direct drive on a horizontal road (marked with index $O$ ). We removed the remote values from the measured compensation measurements, which were obviously unrelated to the car behaviour. The values were averaged. Thus, the values of the longitudinal $a_{x 0}$ and longitudinalacceleration $a_{y 0}$, the height coordinates of the left $H_{30}$ and the right $H_{40}$ side of the body part, the slip angle $\varphi_{0}$ and the turning speed $\omega_{0}$ and the steering wheel turning angle $\beta_{v o}$ we obtained and used for the off-time correction of the measured waveforms from the test drives.

$$
\beta_{i}=\tan ^{-1}\left(\frac{\left(H_{3 i}-H_{3 o}\right)-\left(H_{4 i}-H_{4 o}\right)}{B_{x}}\right) .
$$

The graphical representation of the body tilt angle is in Fig. 3 and it was calculated using relation (3), where $H 3 i(H 4 i)$ is the distance of the measuring point on the left (right) side of the body from the road at the time $t_{i} ; B_{x}$ is the distance of the measuring points in the longitudinalplane of the car; $H_{30}$ $\left(H_{40}\right)$ is the distance of the measuring point on the left (right) side of the body from the road at a constant vehicle speed. 


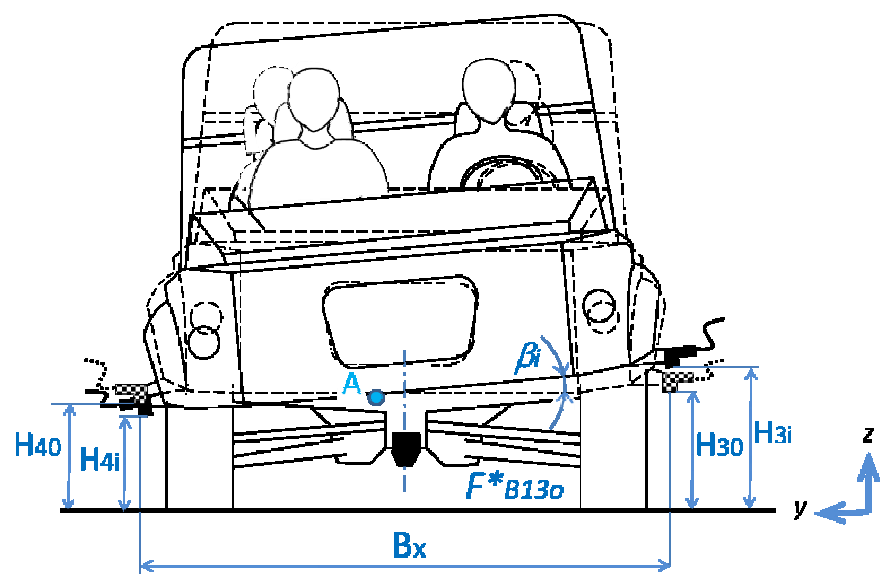

Fig. 4. Plane model of body tilt: $A$-axis ofthe body tilting

Each slalom test drive was performed 10 times for the sake of repeatability. We compared the test results and verified their validity. When processing the measured data, we performed a quick check to see if they corresponded to the expected waveforms. We then removed the remote values. If more than 2 tests were obviously different, we identified the cause and repeated the experiment set. Since these are comparative measurements for each mode of performing the given test drive, it is not necessary to recalculate the measured value waveforms into the centre of gravity of the car.

The measured waveforms of ultrasonic distance sensors were smoothened by means of the moving average at the time interval $t=0.2 \mathrm{~s}$, when a significant distortion of the measured waveform does not yet occur. The signal from the longitudinal and longitudinal acceleration sensors was smoothed by means of the moving average at the interval $t=0.2 \mathrm{~s}$. The car turning speed signal and the slip angle signal were again smoothened using the moving average at a defined time interval, and then subjected to an off-time correction based on the data obtained from the compensation measurement.

The following applies for driving a car in a left bend. The steering wheel turning angle $\beta_{v}$, lateral acceleration $a_{y}$, body tilt angle $\beta_{i}$, and the position of the right side of the body $H P 2$ body have negative values. The angular velocity $\omega$, slip angle $\varphi$, position of the left side of the body $H L 2$, and the car turning angle $\Psi$ have positive values.

\section{Results and discussion}

There are values in the measured properties of the given quantities that are caused by the position of the car due to the car being driven to the experimental measurement at the interval before the car starts. Especially the car appendages are not balanced, but with the so-called prestress caused by braking the car by the service brake. When starting, there is a rapid increase in the longitudinal acceleration. Similar prestress occurs in the car appendages as when braking. We were forced to make a rapid acceleration because of a short starting track. Therefore, the measured quantities are not evaluated in the time interval before entering the test corridor.

The difference in the speeds of driving through the corridor (Fig. 5) is caused by the driver, when the driver perceived the speed as limited on the dashboard and, therefore, on the basis of subjective perception. The steering wheel steering angle $\beta_{v}$ waveform is also determined by the subjective perception of the given corridor by the driver (Fig. 6). To exclude the subjective influence, it is possible to use a driving robot.

The body tilt angle $\beta_{i}$ (Fig. 6) corresponds to the vertical position change values on the sides of the body. The body tilt is limited due to the use of a wheel unit(Fig. 2)under the lower McPherson strut arm. The tilt of the bodywork in the experimental vehicle is up to $3.3^{\circ}$. On the vehicle with SlideWheel, the angle of the bodywork is up to $0.65^{\circ}$. This changes the car suspension kinematics and the body movement is significantly limited compared to the experimental vehicle on the sliding surface. The size of the lateral acceleration $a_{y}$ is lower in SlideWheel than in the experimental vehicle EX. Still, it is obvious that the car was moving at the skid level. The proximity of the skid level is also evident from the steering wheel steering $\beta_{v}$, when it is necessary to turn the steering wheel by a larger 
angle for a similarly high turning velocity $\omega$ (Fig. 9). The change in longitudinal acceleration (Fig. 10) is due to the rapid acceleration before entering the driving corridor of the experimental test, as mentioned above. During the test drive, it is affected by the rotation of the car wheels in the lock position.

From the experimentally measured test drive data it was confirmed that it is possible to reduce the adhesion force transmitted by the car wheels on the road by reducing the weight component on the car wheel with additional wheel units, with unchanged size of the adhesion coefficient. The measured waveforms of typical quantities are similar when comparing the SlideWheel with the sliding surface EX. Significant difference occurs only in the body tilt angle of the experimental car. It is also true for driving on the sliding surface that the car body tilting decreases as the adhesion force transmitted by the car wheel decreases, and the difference in the body tilt angle between the experimental vehicle and the experimental vehicle with the SW system decreases.

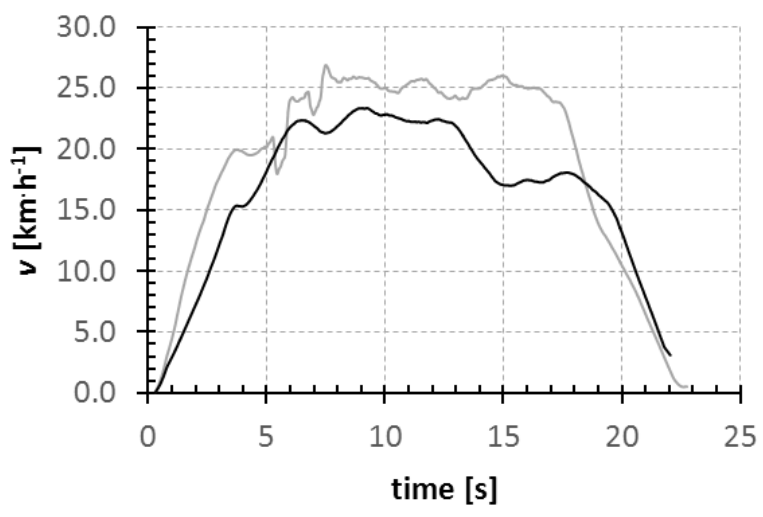

Fig. 5. Speed ofdriving $v:-\mathrm{EX} ;-\mathrm{SW}$

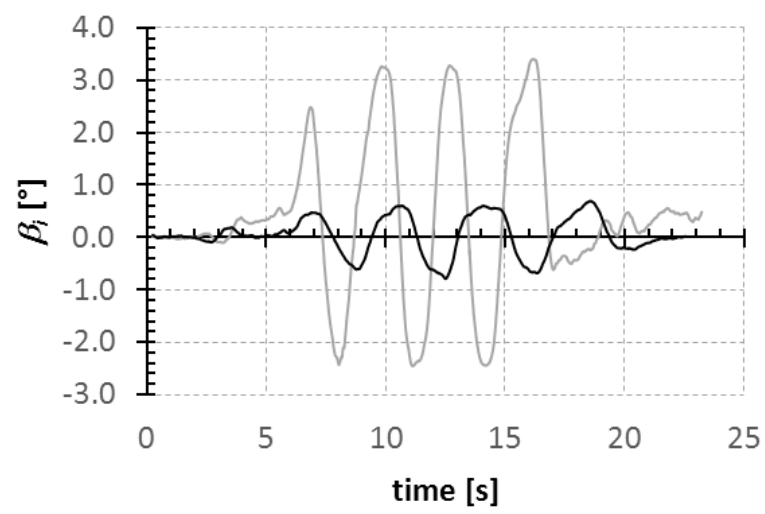

Fig. 7. Body tiltangle $\beta_{i}:-\mathrm{EX} ;-\mathrm{SW}$

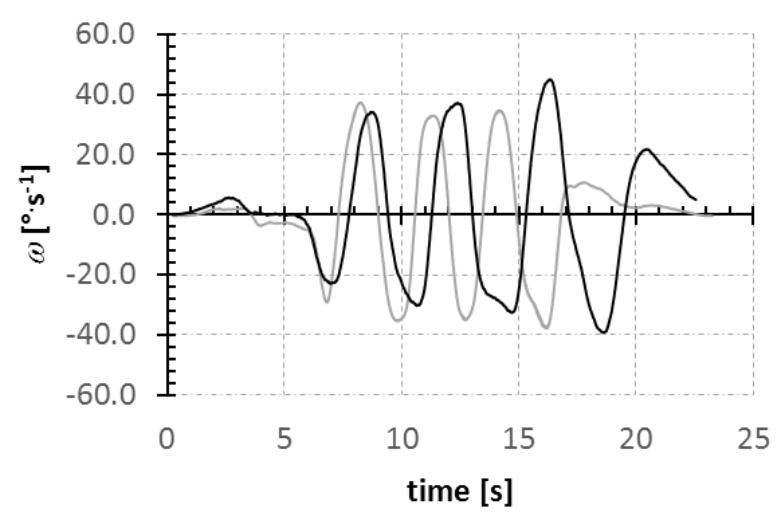

Fig. 9. Turning speed $\omega:-\mathrm{EX} ;-\mathrm{SW}$

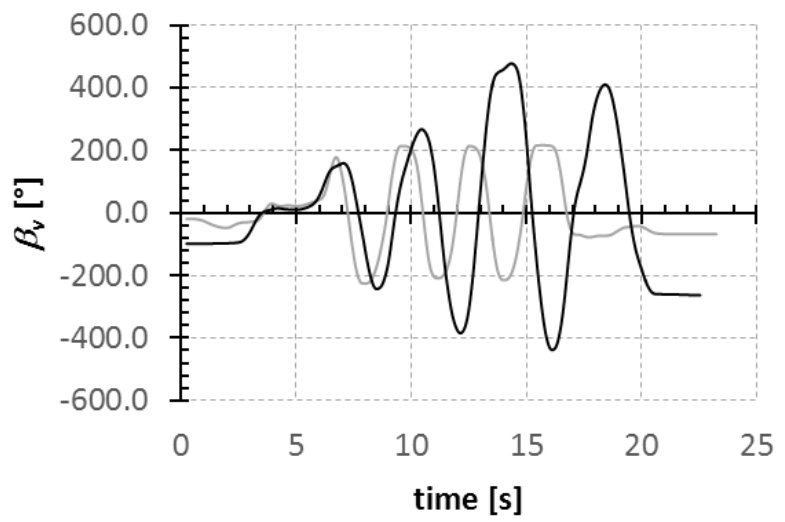

Fig. 6. Steering angle $\boldsymbol{\beta}_{v}$ : $-\mathrm{EX} ;-\mathrm{SW}$

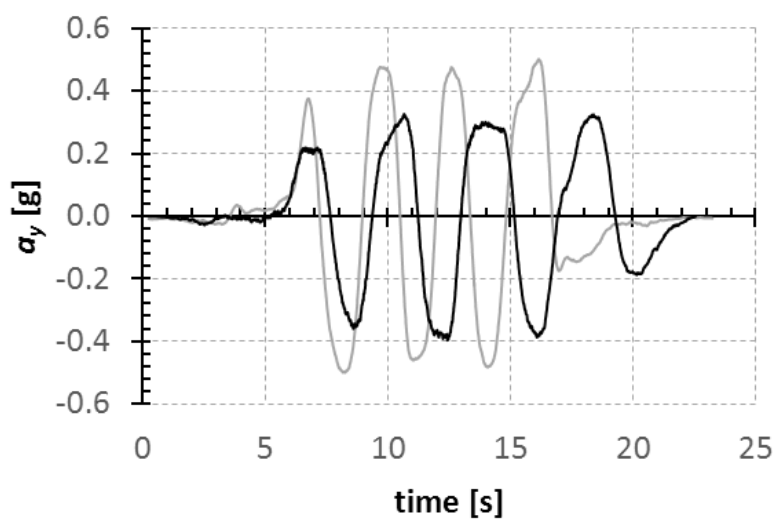

Fig. 8. Lateralacceleration $a_{y}:-\mathrm{EX} ;-\mathrm{SW}$

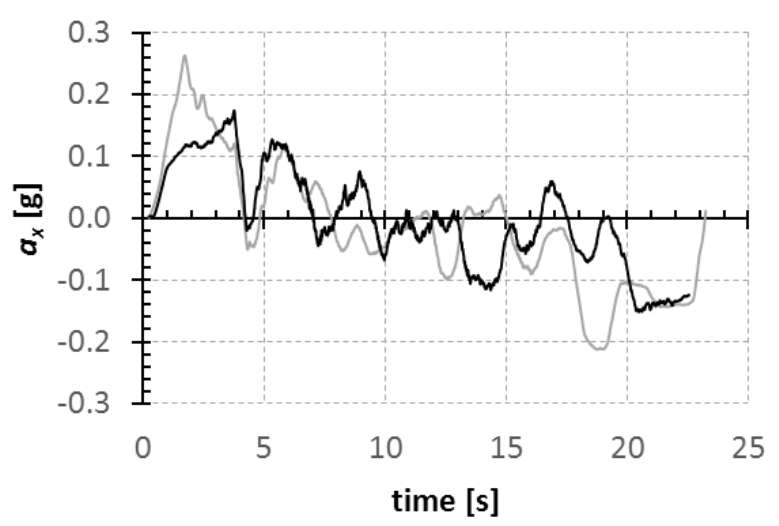

Fig. 10. Longitudinalacceler. $a_{x}:-\mathrm{EX} ;-\mathrm{SW}$ 
The initially designed SlideWheel system used on the experimental car proved to be promising. Despite the fact that the measured waveforms of the body tilt were different, when compared with the sliding surface waveforms. We are creating a dynamic version of SlideWheel at the training workplace, which will allow for a more intense tilting of the car body, and the measured waveforms will be even closer to the sliding surface waveforms. More detailed monitoring of the SW behaviour is the subject for further research.

\section{Conclusions}

1. With SlideWheel, it is possible to change the adhesion force of cars;

2. The body tilt angle is limited compared to the vehicle on the sliding surface;

3. Other measured parameters are mutually consistent between the sliding surface and the SlideWheel system;

4. The SlideWheel system opens new possibilities for testing driver-assistance systems in a limited test space.

\section{References}

[1] Albinsson A., Bruzelius F., Jacobson B. etc. Evaluation of vehicle-based tyre testing methods. Proceedings of the institution of mechanical engineers part d-journal of automobile engineering, vol. 233, 2018, pp. 4-17.

[2] Koštial P., Krmela J., Frydrýšek K. and Ružiak I. The Chosen Aspects of Materials and Construction Influence on the Tire Safety. Composites and Their Properties. Chapter 13, 2012, Rijeka, Chorvatsko, pp. 265-298.

[3] Glos J., Sejkorová M. Tribo diagnostics as and input for the optimization of vehicles preventive maintenance. "Intelligent Technologies in Logistics and Mechatronics Systems, ITELMS 2016Proccedings of the 11th International Conference", April 28-29, 2016, pp. 28-29.

[4] Sejkorová M., Hurtová I., Glos J., Pokorný J. Definition of a motor oil change interval for high volume diesel engines based on its current characteristics assessment. Acta Universitatis Agriculturae et Silviculturae Mendelianae Brunensis, vol. 65(2), 2017, pp. 481-490.

[5] Gao J., Zhang Y., Du Y. etc. Optimization of the tire ice traction using combined Levenberg Marquardt (LM) algorithm and neural network. Journal of the Brazilian society of mechanical sciences and engineering, vol. 41, 2019, pp. 84-96.

[6] Rievaj V., Vrabel J., Synak F. etc. The effects of vehicle load on driving characteristics. Advances in science and technology-research journal, vol. 12, 2018, pp. 142-149.

[7] Šarkan B., Skrúcaný T., Semanová Š. etc. Vehicle coast-down method as a tool for calculating total resistance for the purposes of type-approval fuel consumption. "Scientific Journal of Silesian University of Technology. Series Transport". 2018, 98, 161-172.

[8] Verner J., Sejkorová M. Comparison of CVS and PEMS measuring devices used for stating CO2 exhaust emissions of light-duty vehicles during WLTP testing procedure. "Engineering for Rural Development", May 23-25, 2018, pp. 2054-2059

[9] Lucet E., Lenain R., Grand Ch. Dynamic path tracking control of a vehicle on slippery terrain, Control engineering practice, vol. 42, 2015, pp. 60-73.

[10] Krmela J., Beneš L. and Krmelová V. Tire experiments on static adhesor for obtaining the radial stiffness value. Period. Polytech, 2014, Budapest, Hungary, pp.125-129.

[11] Marek, V., Čupera, J. Data Mining of Vehicle Control Units. "Proceedings of International PhD Students Conference", vol. 23, 2016, pp. 944-948.

[12] Harun M. H., Yunos M. R. Md, Azhari M. A. Validation of Vehicle Model Response with an Instrumented Experimental Vehicle. Engineering "Technology International Conference (ETIC) Engineering technology international conference 2016", August 5-6, 2016, Ho Chi Minh City, Vietnam, pp. 131-136.

[13]Lin F. A New Method for Estimating Road Friction Coefficient. "International Conference on Manufacturing Engineering and Automation", December 7-9, 2010, Guangzhou, China, pp. 26222625. 
[14] Kulička J., Jilek, P. The Fourier analysis in transport application using Matlab. "Transport Means proceedings of the international scientific conference", October 5-7, 2016, Kaunas, Lietuva, pp. $820-825$.

[15] Verner J., Sejkorová M. Comparison of CVS and PEMS measuring devices used for stating CO2 exhaust emissions of light-duty vehicles during WLTP testing procedure. "Engineering for Rural Development", May 23-25, 2018, pp. 2054-2059 